\title{
Tensile Behavior of Normalized Low Carbon Nb- microalloyed Steel in the Presence of Rare Earth Elements
}

\author{
Hadi Torkamani ${ }^{1 *}$, Shahram Raygan ${ }^{1}$, Carlos Garcia Mateo $^{2}$, Jafar \\ Rassizadehghani $^{1 *}$, Yahya Palizdar ${ }^{3 *}$ and David San-Martin ${ }^{2}$ \\ ${ }^{1}$ School of Metallurgy and Materials Engineering, College of Engineering, University of Tehran, Tehran, \\ P.O. Box 11155-4563, Iran \\ ${ }^{2}$ Materalia Research Group, National Center for Metallurgical Research (CENIM), Consejo Superior de \\ Investigaciones Cientificas (CSIC), Avda Gregorio del Amo, 8; Madrid, E-28040, Spain \\ ${ }^{3}$ Materials and Energy Research Center, Karaj, Postal Code: 3177983634, Iran \\ *Corresponding Authors; Email: H.torkamani@ut.ac.ir (Hadi Torkamani), y.palizdar@merc.ac.ir (Yahya \\ Palizdar), Jghani@ut.ac.ir (jafar Rassizadehghani)
}

\begin{abstract}
In this study, attempts have been made to study the effects of RE on the tensile behavior of a low carbon $\mathrm{Nb}$-microalloyed steel which confronts yield point phenomenon during its tensile test. The results of the tensile tests and microstructural examinations presented in this research showed that the upper and lower yield points increase by the RE addition which was mainly attributed to the indirect effects of $\mathrm{RE}$ on the $\mathrm{Nb}$-precipitation manner and refinement of the microstructure. The results also demonstrated that the flow behavior (oscillation in stress level) during the Lüders strain zone is considerably different for the base and RE-added steels. It was found that the RE-added steel undergoes a uniform propagation of the Lüders bands while the base steel showed a distinct non-uninform Lüders strain with rough fluctuations of stress level within this area. This could be due to the uniformity in distribution of nanoprecipitates and solute, e.g. C, atoms in the RE-added steels. Moreover, It was observed that the Lüders strain increases in the presence of RE which could be probably attributed to the finer ferrite grains and the change in nanoprecipitation behavior caused by RE addition. A significant increase in total elongation of the RE-added steel was also observed.
\end{abstract}

Keywords: Rare earth element, Nb-precipitation, low carbon steel, yield point phenomenon, tensile properties.

\section{Introduction:}

Microalloyed ferritic-pearlitic steels are placed in a group of High-Strength Low-Alloy (HSLA) steels which have attained a continuous and ever-increasing development so far $[1,2]$. These steels contain very small amounts of strong carbide or carbonitride-forming elements such as niobium for precipitation strengthening and grain refinement purposes. Carbon content of such steels has been reduced to improve both weldability and toughness, because, the strengthening effects of microalloying elements can compensate 
the strength reduction caused by the reduction in carbon content [1, 3-5]. From the chemical composition point of view, the unique mechanical properties of such steels mainly result from the mere presence of the microalloying elements. These elements provide a combination of strengthening mechanisms that serve as obstacles for dislocation movement during deformation processes [6,7]. Among these, niobium is the more effective strengthening element, able to strongly increase the yield strength by precipitation hardening and by promoting the grain refinement of ferrite grains [8-13].

In addition to the precipitation hardening promoted by these microalloying elements, the fineness of the microstructural components would also affect the tensile behavior. It has been reported that grain refinement of proeutectoid ferrite would favorably contribute to the strength and toughness properties of the steels [14-17]. The reduction in the pearlite nodule size would also contribute to the enhancement of the steels strength $[15,18]$. Besides, in the low carbon steels, where pearlite coexists with ferrite in the microstructure, the contribution of pearlite volume fraction to the strength is considered to obey the law of mixtures $[14,16,17]$.

The characteristic tensile behavior of polycrystalline materials consists in a smooth transition from the elastic to the elastic-plastic region with a steadily rising stress-strain curve, prior occurrence of necking. While, low carbon steels display a rheological behavior at the beginning of plastic deformation where an abrupt transition from the elastic to elastic-plastic state with a characteristic drop in the stress-strain curve takes place [19]. This is referred to the yield point phenomenon, and is associated with the occurrence of Lüders bands. However, for some applications, in order to improve the deep drawability and surface quality, continuous yielding (elimination of Lüders bands) is usually preferred [20]. The main reason for appearance of Lüders bands in such steels is the pinning of dislocations by the dissolved $\mathrm{C}$ and $\mathrm{N}$ atoms which form the so-called Cottrell's atmospheres [20, 21].

In steel industry, Rare Earth elements (RE) are known as strong inclusion modifiers [2225]. There are abundant published reports dedicated to the effects of RE on tensile property of steels [26-29]. Some of these works show contradictory results regarding the effects of RE on the strength which implies somehow that there is no clear relationship between the tensile strength and the amount of RE in steels. However, a consensus regarding the positive effect of $\mathrm{RE}$ on elongation and toughness properties exists in the literature [26, 28, 30, 31]. Despite the extensive studies carried out in this field, the effect of RE on the tensile behavior of low carbon Nb-microlloyed steels, which is talented to undergo a yield point phenomenon, has not been studied so far and the conducted experimental reports suffer from a lack of proper discussion and explanation.

In a recent work of the authors, it has been found out that RE addition to such a low carbon microalloyed steel would refine the pearlite nodules and ferrite grains [32]. In a separate report, the authors have also showed and discussed that RE would affect the fraction, roundness factor, and size of the inclusions that exist in low carbon steels [33]. Besides, it has been reported that $\mathrm{RE}$ are able to affect the solubility of $\mathrm{Nb}$ and change the $\mathrm{Nb}$-precipitation manner in microalloyed steels [33-35]. Regarding the effect of $\mathrm{Nb}$ precipitation on the tensile behavior, Reskovic and Jandrlic [19] have claimed that the severity of Lüders effect is influenced by the presence and distribution manner of $\mathrm{Nb}$ precipitates in microalloyed steels. 
One can deduce that, more attention should be paid to the use of RE in steels aimed at playing roles in transformations taken place in steels rather than their sole influence on inclusion modification. Hereupon, encouraged by an extensive literature research and net results obtained from our works concerned with RE addition to the normalized steels, in this study, a misch metal (containing $\mathrm{Ce}$ and $\mathrm{La}$ ) was added to a low carbon $\mathrm{Nb}$ microalloyed steel to elucidate their influence on the tensile behavior. In fact, this study mainly focuses on the unraveled influences of $\mathrm{RE}$ on the $\mathrm{Nb}$ precipitation manner and its consequences on the tensile behavior which would be associated with a change in the yield point phenomenon. Detailed microstructural examinations enabled us to discover the link between the addition of RE and the tensile behavior of the steel under investigation; the addition of RE to low carbon microalloyed steels would change the microalloying precipitation manner (by inclusion modification), which in turn will have an impact on their tensile behavior (especially the Lüders effect). Since the Lüders effect/yield point phenomenon is an important factor interfering with deformation process of low carbon steels, the outcomes of this study could shed light on the advantages and drawbacks of RE addition to such steels.

\section{Experimental procedure}

\subsection{Materials:}

Two experimental cast steels were produced in a melting induction furnace with a holding capacity of $100 \mathrm{~kg}$. A clean scrap steel was charged into the furnace in an openair atmosphere. Alloying elements were adjusted after complete melting. Aimed at producing the base low carbon microalloyed steels, ferroniobium $(65 \mathrm{wt} . \% \mathrm{Nb})$ and ferrovanadium ( $80 \mathrm{wt} . \% \mathrm{~V})$ were added to the melt and the carbon and Mn contents of the steel were adjusted at 0.15 and $1.0 \mathrm{wt}$. \%, respectively. After alloying, the melt was deoxidized with $\mathrm{Al}$ shots, then, poured into two separate carrying ladles. A total of $7 \mathrm{~g}$ of Misch metal, containing 62.1 wt. \% Ce and 37.8 wt. \% La, had been placed at the bottom of one ladle in order to obtain steels with a same base composition while one of them contains RE. The base chemical composition of the produced steel was measured by Optical Emission Spectrometry (OES: ARL 3460) technique, results of which are given in Table 1. The melts were cast into sand molds with Y-block cavities inside. The amount of RE that remained in the casts was measured by Inductively Coupled Plasma (ICP: OPTIMA 7300 DV); the results are listed in Table 2. This table also gives oxygen and nitrogen content in the studied steels, which has been measured using a gas analyzing equipment model LECO TC-436 AR.

Table 1: Chemical composition of the base steel (Fe to balance)

\begin{tabular}{cccccccccccc}
\hline Elements & $\mathrm{C}$ & $\mathrm{Si}$ & $\mathrm{Mn}$ & $\mathrm{S}$ & $\mathrm{P}$ & $\mathrm{V}$ & $\mathrm{Nb}$ & $\mathrm{Mo}$ & $\mathrm{Cu}$ & $\mathrm{Al}$ & $\mathrm{Cr}$ \\
\hline wt. \% & 0.16 & 0.30 & 1.00 & 0.01 & 0.02 & 0.11 & 0.05 & 0.01 & 0.09 & 0.04 & 0.06 \\
\hline
\end{tabular}

Table 2: $\mathrm{RE}$ ( $\mathrm{La}$ and $\mathrm{Ce}$ ), $\mathrm{O}$ and $\mathrm{N}$ content in the base and RE-added steels

\begin{tabular}{cccccc}
\hline \multirow{2}{*}{ Steels } & \multicolumn{5}{c}{ Elements, in ppm } \\
\cline { 2 - 6 } Base & $\mathbf{C e}$ & $\mathbf{L a}$ & $\mathbf{C e}+\mathbf{L a}$ & $\mathbf{O}$ & $\mathbf{N}$ \\
RE-added & 127.0 & $<10$ & --- & $96 \pm 10$ & $113 \pm 4$ \\
\hline
\end{tabular}


The ingots experienced homogenizing treatment at $1100{ }^{\circ} \mathrm{C}$ for $5 \mathrm{~h}$ and then cut samples were normalized at $950{ }^{\circ} \mathrm{C}$ for $30 \mathrm{~min}$. The heat treatment cycles were performed in a muffle furnace (model: AZAR M11L) under the air atmosphere.

\subsection{Microstructural examinations:}

Prior to the microstructural examination, steel samples were prepared according to the standard metallography procedures. The samples were first ground and then polished with diamond paste. This polishing process was carried out using a lubricant (a mix of ethanol and DP-Lubricant Blue) so as to protect the surface from oxidation and also avoid removal of the inclusions from the surface of the samples. Inclusion observation by means of Scanning Electron Microscopies (SEM, model: QUANTA 450) in both Secondary (SE) and Back Scattered-Electron (BSE) modes, was carried out on the samples in the polished condition to obtain a better contrast between the inclusions and matrix. The microscope was equipped with an Energy Dispersive X-ray Spectrometer (EDS, model: Xflash 6L10) unit for performing the microanalysis on the inclusions and precipitates.

An Optical Microscope (OM: NIKON ECLIPSE LV150N) was utilized to take images from the polished surface in order to characterize the inclusions i.e. to measure their size, area fraction and roundness factor. An image analysis software (ImageJ 1.47v) was used to measure these parameters on at least $5 \mathrm{OM}$ images at a same magnification. The contrast between inclusions and the polished surface has favorably helped the exposure of the inclusions, making it easy to measure their area and area fraction. The details of the methodology employed to characterize the inclusions has been described in our previous work [33]. However, the inclusions were also observed under the OM in etched condition to monitor any possible influences of RE on the micro-precipitation. For this reason, the polished samples were etched with Nital $2 \%$ solution to reveal the microstructures of the steels.

The size of ferrite grains and pearlite nodules has been measured on several (at least 5) OM images taken from the etched surfaces. With this aim, the phase boundaries were precisely delineated using GIMP (version 2.8) image analyzing program. Then, these processed images were used as input to the ImageJ program to measure the area and area fraction of ferrite and pearlite. It is worth mentioning that the size of inclusions, ferrite grains and pearlite nodules (d) has been calculated from their area (A) according to $\mathrm{d}=2 \sqrt{ }(\mathrm{A} / \pi)$; for this calculation, these microstructural components have been assumed as circular particles.

Close observations and monitoring of the nano-precipitation behavior in the studied samples were carried out using a TEM (model: JEOL JEM 3000F) equipped with EDS Oxford INCA unit. For this reason, some samples were prepared from $3 \mathrm{~mm}$ diameter discs which had been ground to $\sim 80 \mu \mathrm{m}$ thickness. The tiny discs were electropolished afterwards by Tenupol 5 using 95/5: acetic/perchloric acid electrolyte at room temperature and the voltage of $40 \mathrm{~V}$.

\subsection{Tensile tests:}

Tensile tests were performed three times on the normalized samples by using a GOTECH 
AL-7000 LA 30 tensile machine and the average was reported. A pair of grips shown in Figure 1a was used to tension the specimens at a constant strain rate of $0.0005\left(\mathrm{~s}^{-1}\right)$ to avoid sliding of the specimens over the grips during the tensile tests. Subsize tensile specimens were prepared according to ASTM E8-04 standards, which were carefully grinded before performing the test in order to remove any scratches remained from sample preparation and also the thin surface layer possibly decarburized during the austenitization process. Schematic of the tensile sample is shown in Figure 1b. During the tensile testing, load-displacement curves were continuously recorded which were converted to engineering stress-strain curves. The recorded displacement corresponds to the displacement determined by the machine crosshead motion.

a)

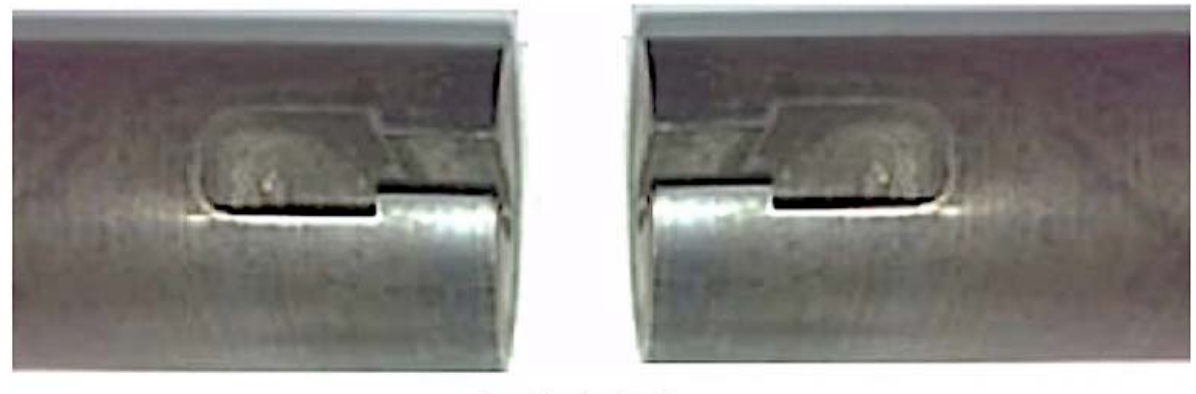

b)

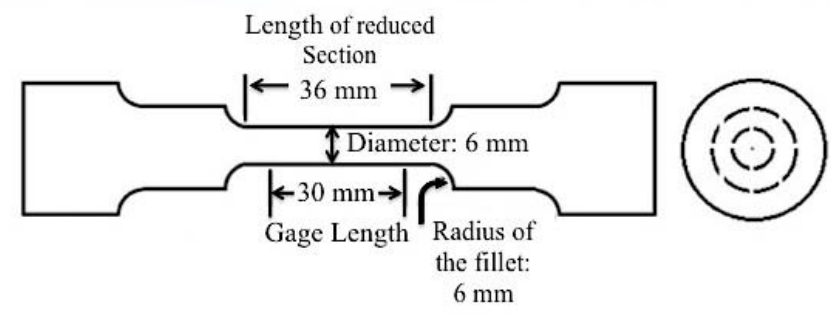

Figure 1: a) tensile test grips used for stretching the specimens and b) schematic of the tested specimens.

\section{Results and discussion:}

\subsection{Microstructural characterization in the presence of RE:}

\subsubsection{Characterization of pearlite and ferrite:}

In low carbon steels, as it was discussed in the introduction, both ferrite and pearlite constituents would affect the tensile properties; refinement of ferrite grains and pearlite nodules are beneficial to the tensile and toughness properties [14-17]. Figure 2 illustrates the microstructures of the normalized steels consisting of pearlite nodules in the ferrite matrix. Compared to the base steel (Figure 2a), a finer distribution of pearlite nodules can be observed in the microstructure of the RE-added steel (Figure 2b). The data obtained from the characterization of these components are given in Table 3, which shows that RE addition could lead to a refinement of ferrite and pearlite, while its effect on the volume fraction of perlite is insignificant. This refinement is mainly derived from the refined cast structure obtained by RE addition. In a previous work of the authors, the eligibility of RE-inclusions to serve the solidification nucleation sites have been assessed and it was found that RE are able to refine the cast structure and consequently the Prior Austenite Grain Size (PAGS) [36]. The nodule size is determined by the transformation temperature and PAGS; the higher the transformation temperature and/or the coarser the 
PAGS, the larger nodule size would be [37-39]. Since the heat treatment condition, e.g. cooling rate, has been similar for both steels, the finer features observed in RE-added steel should be derived from the finer parent austenite. The magnified image in Figure 2b illustrates fine pearlite nodules nucleated on the boundaries of fine grains, which have been often observed in the microstructure of the RE-added steel. In another recent work of the authors, the positive contributions of RE addition to the refinement of pearlite structure have been discussed in detail [32].

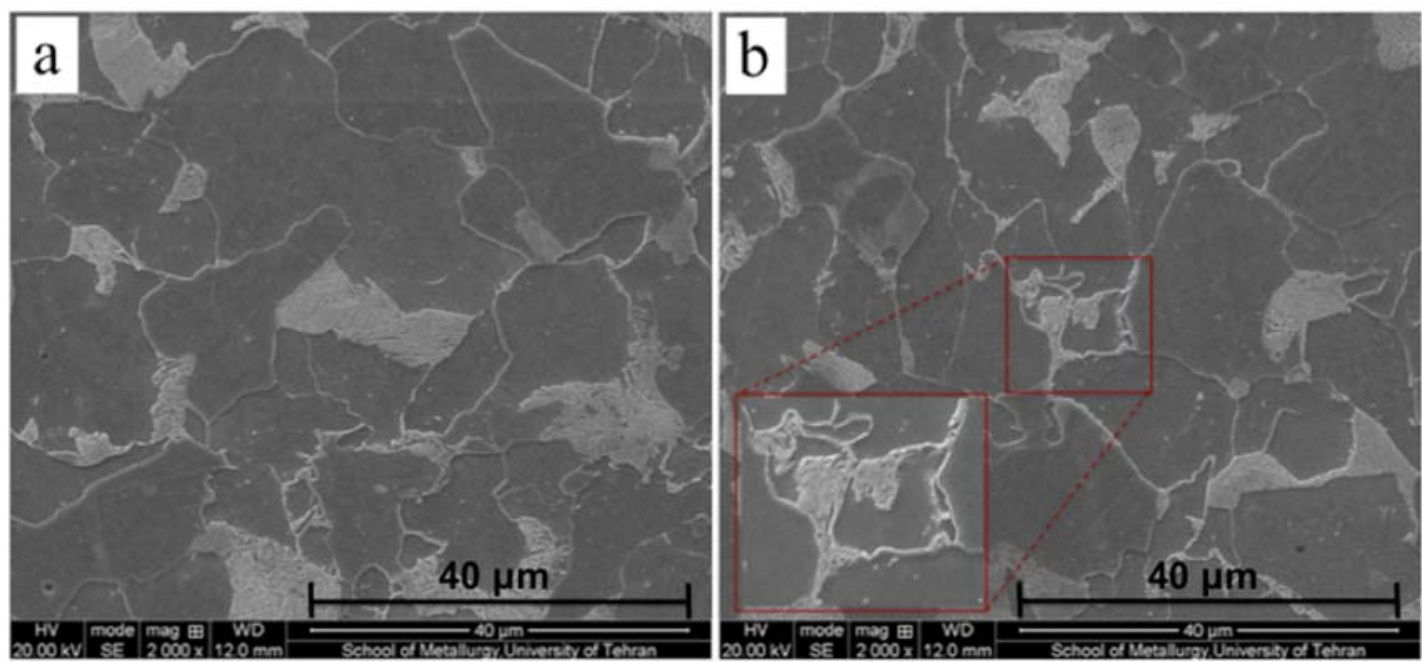

Figure 2: distribution of pearlite nodules in the matrix of normalized a) base and b) RE-added steels (magnified image shows the fine pearlite nodules nucleated on the boundaries of fine prior grains).

Table 3: The microstructural characteristics of the normalized samples

\begin{tabular}{cccc}
\hline Steels & $\begin{array}{c}\text { Average of pearlite } \\
\text { nodule size, } \boldsymbol{\mu m}\end{array}$ & $\begin{array}{c}\text { Average of ferrite } \\
\text { grain size, } \boldsymbol{\mu m}\end{array}$ & Pearlite $\%$ \\
\hline Base & $9 \pm 0.4$ & $12 \pm 0.6$ & $23 \pm 0.8$ \\
RE-added & $6 \pm 0.3$ & $7 \pm 0.4$ & $21 \pm 0.9$ \\
\hline
\end{tabular}

During the inspection of the normalized steels under the OM, it was likely to find inclusions within the microstructures. Some OM images were intentionally taken from the areas including large inclusions in the matrix. Figure 3 illustrates such inclusions present in the microstructure of the base steel. Looking deeper into the microstructure of this sample, at the left part of this figure (magnified image), it can be seen that some white areas are accumulated around the inclusion particle. It is worth mentioning that these white areas are only observed around the particles in gray color.

Figure 4 illustrates an image including a large characteristic inclusion found in the microstructure of the RE-added steel. In contrast to the microstructure of the base steel, the inclusions present in the microstructure of RE-added steel demonstrate no accumulations of white phases/areas around them. To identify the particles that exist in the microstructure of the studied steels, especially the white areas/phases surrounding the gray inclusions noticed in Figure 3, EDS technique has been employed. Their results will be provided in the next subsection. 


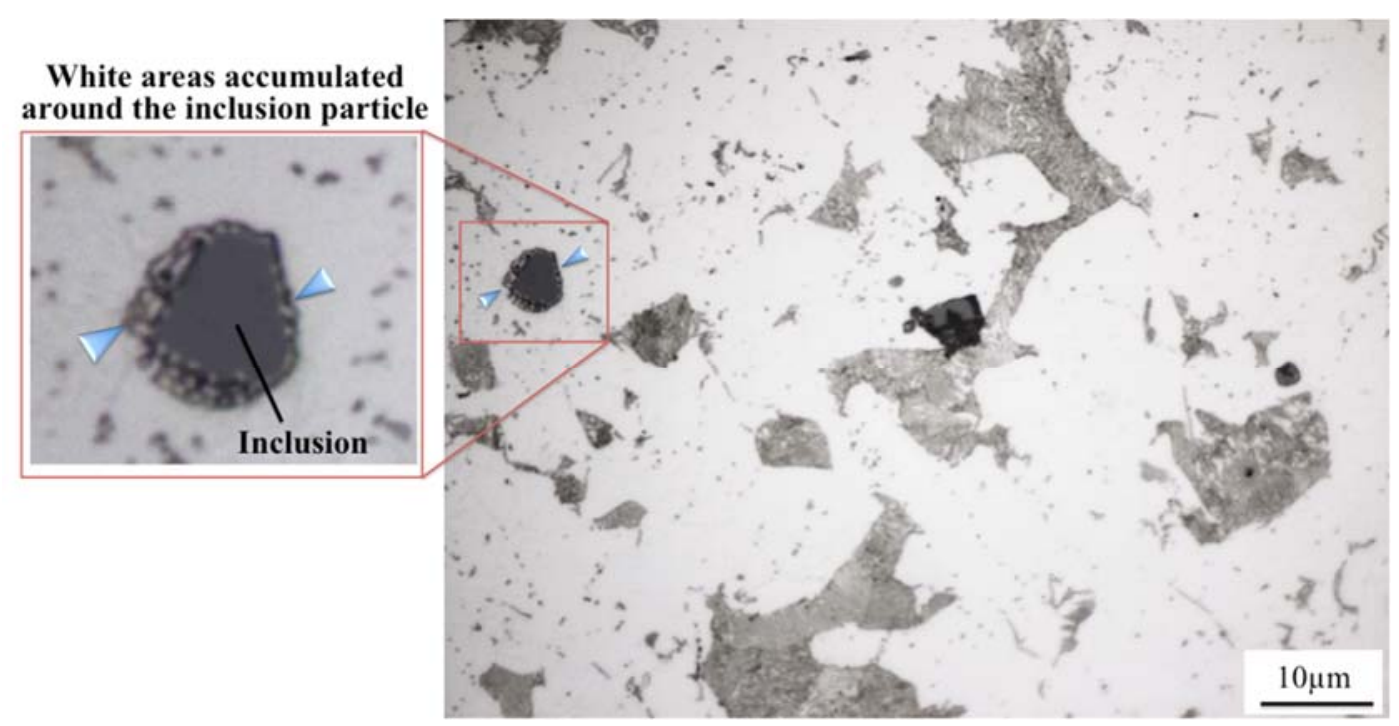

Figure 3: OM image showing white areas surrending relatively large inclusion (magnified image) present in the microstructure of the base steel.

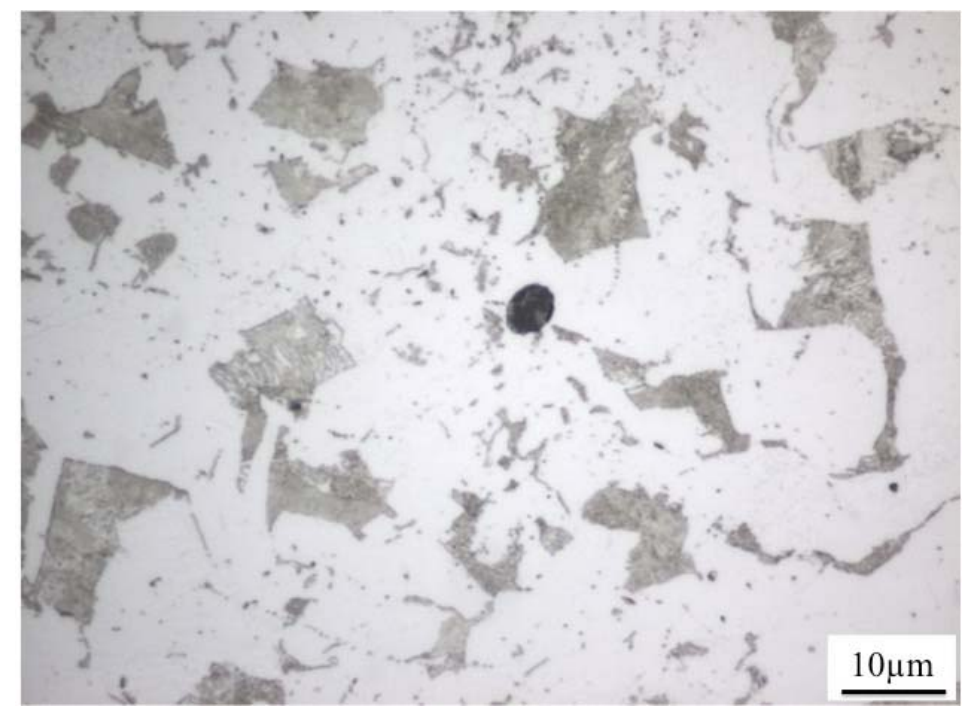

Figure 4: A typical inclusion obsereved in the microstructure of RE-added sample.

\subsubsection{Inclusion characterization:}

Rare earth elements are well known as inclusion modifiers in steels. In a recent work of the authors, inclusion modification by RE has been deeply studied [33]. It has been found out that addition of $200 \mathrm{ppm}$ of RE is able to reduce the average size (from 1.31 to 1.24 $\mu \mathrm{m}$ ) and area fraction (from 0.123 to $0.105 \%$ ) of the inclusions and also change their morphology to a more spherical shape. Figure 5 shows a characteristic inclusion appeared in the microstructure of the base steel. SEM images, in BSE (Figure 5a) and SE (Figure 5b) imaging modes, show some bright areas around the darker phase. The microanalyses result of the spots (Figure 5c) approves the accumulation of $\mathrm{Nb}$-rich phases around $\mathrm{MnS}$. It has been proposed that this phenomenon could be attributed to the difference in thermal expansion coefficients between matrix (ferrite) and $\mathrm{MnS}$ particles 
and subsequent debonded area between them at high temperature (in pasty region) during the solidification process [33]. This inclusion seems to be identical to the one shown in Figure 3 (in the magnified image), where a considerable amount of white areas was observed around the gray particle. Now, according to the EDS results (Figure 5c and d), those areas are believed to be Nb-rich phases, likely as $\mathrm{NbC} / \mathrm{Nb}(\mathrm{C}, \mathrm{N})$, accumulated on the outer surface of MnS. According to both OM and SEM images (Figure 5), one can anticipate that, since the size of the segregated areas are in the micrometer scale, a significant amount of $\mathrm{C}$ and $\mathrm{Nb}$ has probably been consumed to form these large precipitated areas.

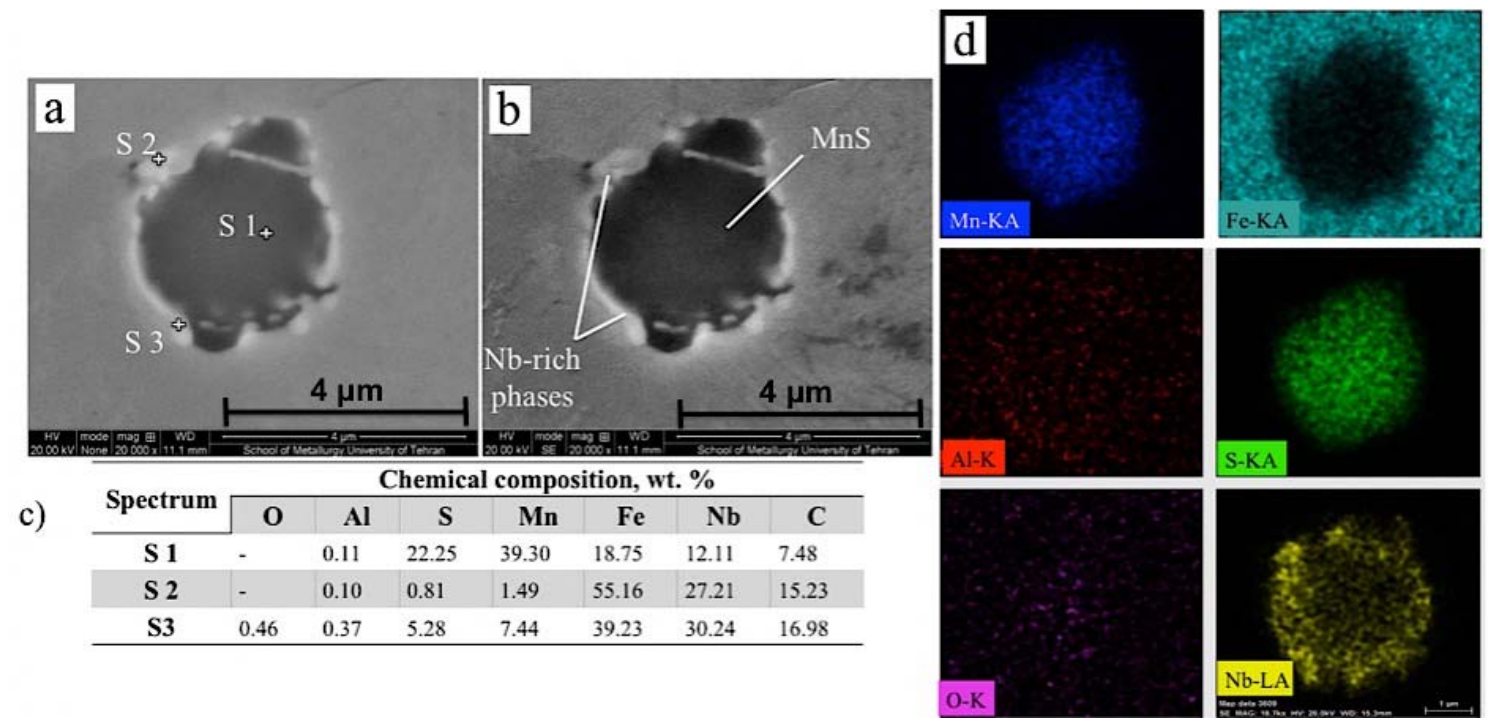

Figure 5: a) and b) SEM images of an inclusion in BSE and SE modes, respectively, c) the results of EDS microanalyses of the spectra, and d) Elemental mappings of the inclusion showing significant $\mathrm{Nb}$ segregation around $\mathrm{MnS}$ in the base steel.

It has been reported that the $200 \mathrm{ppm}$ addition of RE to a similar steel could change the inclusions matrix from $\mathrm{MnS}$ to (RE)S, where accumulation of Nb-rich phases in the outer surface of the inclusions have been inhibited [33]. It has been also found out that REinclusions do not seem to serve the preferential sites for the accumulation of $\mathrm{Nb}$-rich phases since the thermal expansion coefficient of RE-particles is close to that of ferrite matrix $[22,40]$. For more explanations of the phenomena taken place in the presence of $\mathrm{RE}$, the reader is referred to our previous work [33].

According to the current results, one can conclude that the elimination of the large $\mathrm{Nb}$ segregated areas by $\mathrm{RE}$ addition would influence the amount of solute $\mathrm{Nb}$ and $\mathrm{C}$ in the matrix. This would have an impact on the $\mathrm{Nb}$-nano precipitation manner and consequently on the tensile behavior of the steel under investigation.

\subsection{Effects of RE on the tensile behavior of the normalized steels:}

Figure 6 demonstrates representative engineering stress-strain curves for the base and REadded steels. The tensile curves of the both steels start with elastic region and then reach to the yield point. Following this point, stress level falls in a lower level, encountering yield point phenomenon. After these distinct upper and lower yield points, a complex 
rheological behavior can be observed in the tensile curves. Shape of this area (Lüders region) is different for the studied steels. The yield point phenomenon during the tensile tests is often referred to the Lüders effect, through which, the plastic deformation bands are considered as Lüders bands, and the plastic strain within the bands as Lüders strain [41]. Having passed the Lüders region, the curves continue in a normal behavior with increasing the stress level till reaching the maximum level considered as Ultimate Tensile Strength (UTS). After that, during necking, the stress levels drop till final rupture.

As mentioned above, to form the Cottrell atmosphere, $\mathrm{C}$ and/or $\mathrm{N}$ need to segregate to the dislocations and pin them. Therefore, a small extra force (stress) is required to unpin them, producing the upper and lower yield points in the tensile curves. It has long been understood that a minimum addition of microalloying elements to Extra Low Carbon (ELC) steels is required in order to effectively stabilize $\mathrm{C}$ and $\mathrm{N}$ by forming carbides, nitrides and/or carbonitrides, which would lead to the elimination of the Cottrell's atmosphere and achievement of a continued yielding behavior [42]. However, as it has been observed in Figure 6, in the low carbon microalloyed steels, enough carbon would be available in solid solution for the occurrence of yield point phenomenon.
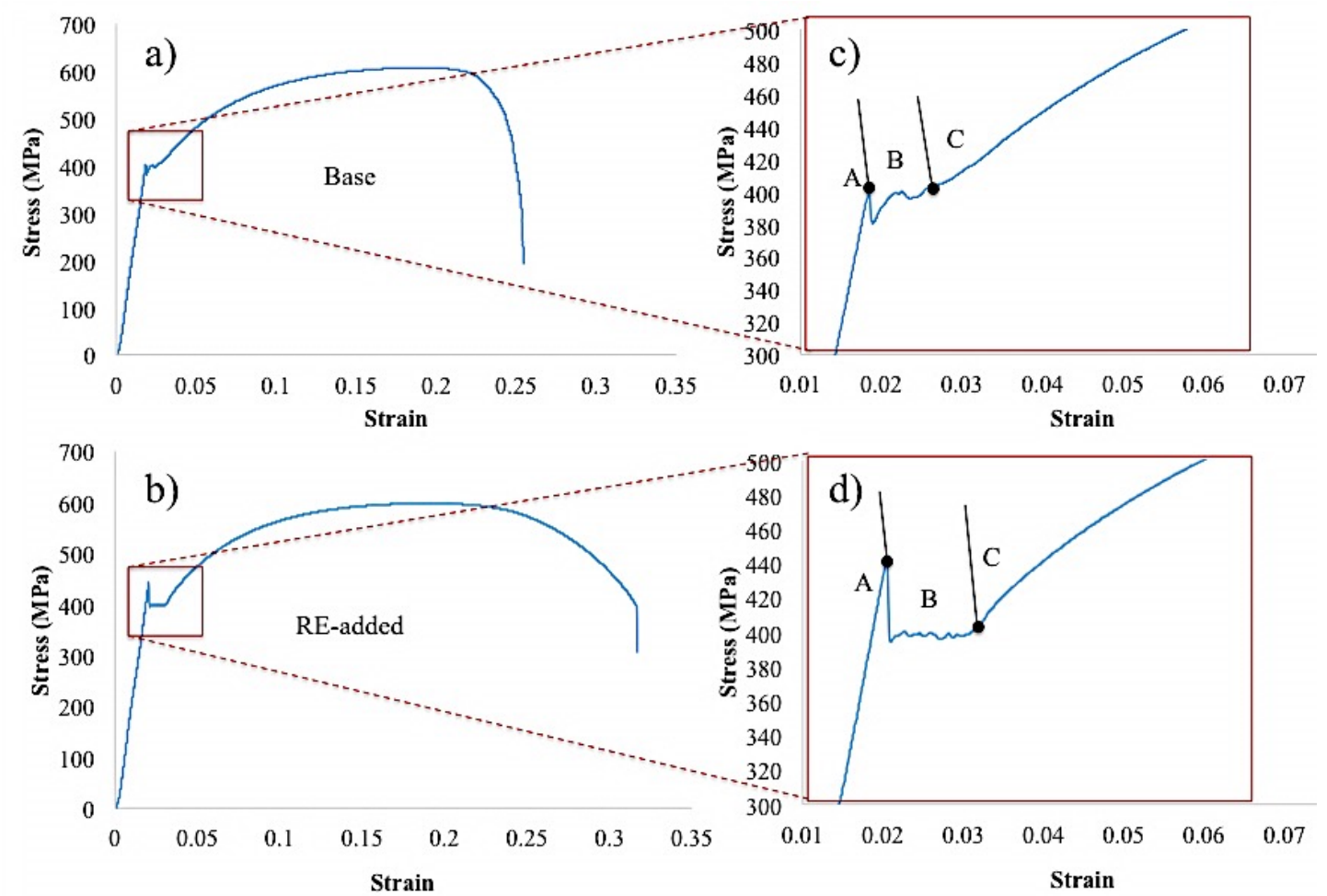

Figure 6: Engineering stress-strain curves for the a) base and b) RE-added steels along with enlarged divided area including yield point phenomenon for the c) base and d) RE-added steels.

The mechanical properties estimated from the tensile tests (Figure $\mathbf{6 a}$ and $\mathbf{b}$ ) are given in Table 4. It can be seen that the RE addition leads to an enhancement of the total elongation of the steel as well as an increase in the yield points, while its effect on Ultimate Tensile Strength (UTS) is negligible. Tuttle [29] also found out that this property (UTS) remains almost unchanged by the RE addition, while this outcome has not been discussed in that work. 
Table 4: The results of tensile test for the studied steels

\begin{tabular}{cccccc}
\hline $\begin{array}{c}\text { Normalized } \\
\text { Steels }\end{array}$ & $\begin{array}{c}\text { Upper yield } \\
\text { point, MPa }\end{array}$ & $\begin{array}{c}\text { Lower Yield } \\
\text { point, MPa }\end{array}$ & $\begin{array}{c}\text { UTS, } \\
\mathrm{MPa}\end{array}$ & $\begin{array}{c}\text { Lüders Strain, } \\
\left(* 10^{2}\right)\end{array}$ & Elongation, \% \\
\hline Base & $395 \pm 7$ & $374 \pm 6$ & $603 \pm 8$ & $0.8 \pm 0.1$ & $25 \pm 1$ \\
RE-added & $440 \pm 6$ & $399 \pm 7$ & $598 \pm 7$ & $1.3 \pm 0.1$ & $32 \pm 2$ \\
\hline
\end{tabular}

Unveiling why RE addition increases the yield points but not the UTS could be explained in the following way. The yield strength strongly depends on microstructural features such as the matrix grain size and the presence of precipitates (their size and type). The UTS is more affected by work hardenability, which is directly dependent on the Stacking Fault Energy (SFE). Although the grain size and precipitates affect the work hardening of metals, the effect of SFE seems to be much more important than these microstructural features in controlling the tensile strength derived from its significant effect on work hardening $[43,44]$.

It should be mentioned that the microstructure of the normalized steels consists of pearlite in a matrix of ferrite. In steels with such microstructures, yielding happens in ferrite phase, which is supposed to provide the ductility as well. The bec ferrite phase has numerous slip systems and a high SFE (a low hardening exponent); facilitating dislocation cross-slip [44]. This, in turn, means that strain hardening of this phase is originally low. To the authors' knowledge, there is little information in the literature concerned with the direct effect of RE on SFE of ferrite. Although significant change in grain size and precipitation manner might have an impact on the work hardening rate, according to the model proposed by Morrison [45] (equation 1), refining the grain size (d) from 12 to $7 \mu \mathrm{m}$ (achieved by RE-addition) would alter the hardening exponent (n) only about 0.03 . Moreover, it has been reported elsewhere that, depend on the characteristics of the microalloying precipitates like their size and fraction, they may have great or no influence on the hardening exponent [46].

$n=5 /\left(10+d^{-1 / 2}\right)$

Figure 7 illustrates the representative true stress-true strain curves for the studied steels, which correspond to the plastic deformation area up to uniform elongation, i.e. before necking. Through this area, it can be realized that the plastic/work hardening behavior is almost the same for the base and RE-added steels. 


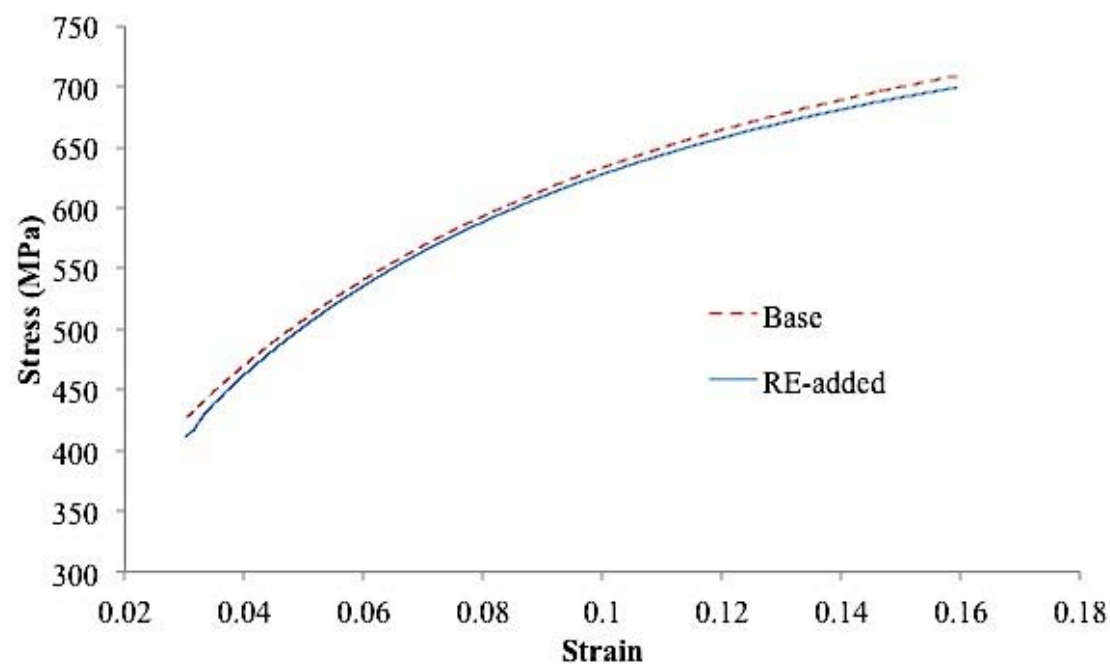

Figure 7: True stress versus true strain curves belonged to the plastic region up to uniform elongation.

For a better understanding of the phenomena taking place during the tensile tests of the studied steels, the tensile curves around the yield point can be divided into three zones as illustrated in Figure $\mathbf{6 c}$ and d. This subdivision has been proposed according to the results of the thermovision tests carried out on Nb-containing steels by other researchers $[19,47$, 48]. These zones have been labelled as A, B and C in Figure 6c and $\mathbf{d}$. The Lüders bands form once the stress level drop to the lower yield point $[41,48]$, at the beginning of zone B.

It is well-known that the yield strength is determined by several microstructural parameters like volume fractions of phases, their size, presence of precipitates and dislocations. Thus, the differences found between both steels would have to be explained based on these parameters. Given the small difference in the volume fraction of ferrite and pearlite between both steels (Table 3), the influence of this parameter can be regarded as negligible. Thus, among the rest of the microstructural parameters, the grain refinement would be the main way of enhancing the yield strength $[2,3,15]$. In this regard, Table 3 shows that the RE addition could reduce the size of ferrite grains and pearlite nodules from 12 to $7 \mu \mathrm{m}$ and 9 to $6 \mu \mathrm{m}$, respectively. The promotion of nanoprecipitation is another way used to increase significantly the yield strength in microalloyed steels $[3,7,10,49]$. In the same sense, it has been reported that, the pinning of dislocations by niobium nanoprecipitates would increase the stress in zone A, contributing to the formation of the Lüders bands at higher stress level and leading to the higher upper yield point [19]. As it was discussed in the previous sections, RE addition changes the nature of the inclusions from $\mathrm{MnS}$ and/or $\mathrm{MnS}-\mathrm{Al}_{2} \mathrm{O}_{3}$ to RE-base. The addition of $200 \mathrm{ppm}$ of RE seems to inhibit the formation of MnS particles, which in Figure 3 Figure 5 has been noticed to serve as the preferential nucleation sites for the nucleation of large $\mathrm{Nb}$-precipitates. Without the presence of $\mathrm{MnS}$ in the RE-added steel, $\mathrm{Nb}$ and $\mathrm{C}$ would remain in solid solution in the matrix at high temperatures, and available for nanoprecipitation as $\mathrm{Nb}(\mathrm{C}, \mathrm{N})$ during cooling in the austenite and ferrite. As it has been discussed, compared to the base steel, the presence of these nanoprecipitates would 
increase the yield strength in the RE added steel. To determine whether these Nbprecipitates are present in the microstructure or not, both steels have been inspected using TEM-EDS. Figure 8 and Figure 9 show TEM images along with the results of the microanalyses performed on some selected spots, in the base and RE added steels, respectively. In Figure $\mathbf{8}$ only some scattered precipitates are visible in the ferrite matrix of the base steel. The microanalyses reveal the presence of both $\mathrm{Nb}$ and $\mathrm{V}$ in the composition. In contrast, the TEM image and microanalyses shown in Figure 9 unveil the presence of an extensive nanoprecipitation of $\mathrm{Nb}$-rich phases in the ferritic matrix of the RE-added steel. The different state of precipitation is a direct consequence of the effect of RE on the type of inclusions formed during the casting of the alloys. While in the base steel most of the $\mathrm{Nb}$ seems to precipitate as coarse particles around $\mathrm{MnS}$ inclusions, in the RE-added steel the inhabitation or negligible formation of $\mathrm{MnS}$ prevents the precipitation of $\mathrm{Nb}$ around inclusions. As a consequence, the amount of $\mathrm{Nb}$ in solid solution available for precipitation during cooling is much greater in the REadded steel. Thus, based on what was explained above, pinning of dislocations by these nanoprecipitates in RE-added steel, would contribute to increasing of the upper yield point (Table 4).

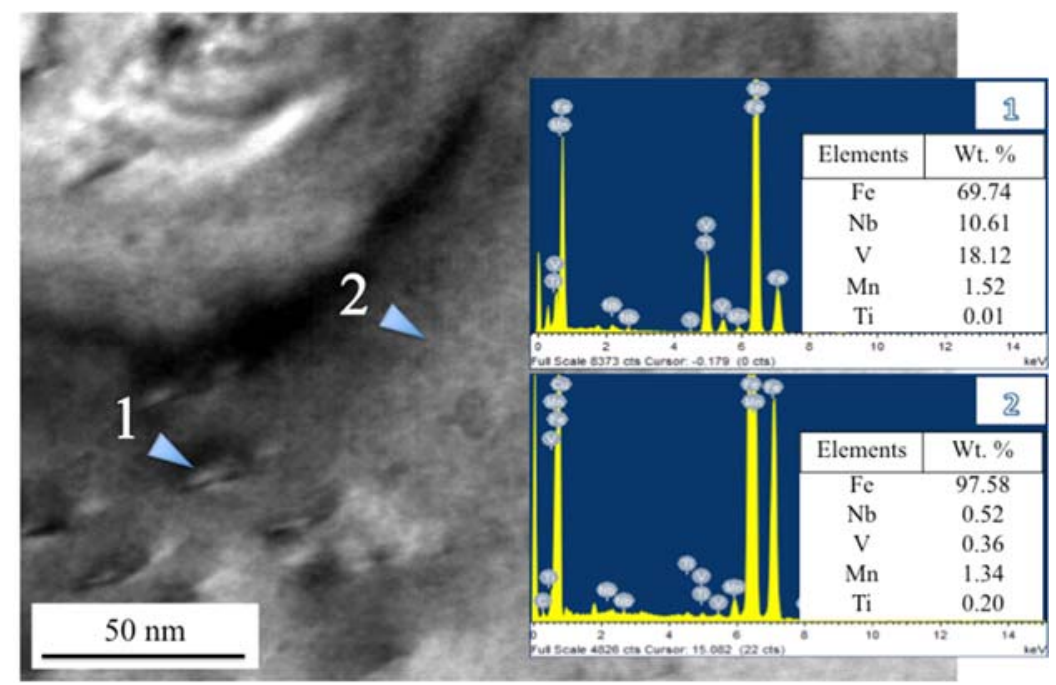

Figure 8: TEM image of the base steel along with the results of EDS microanalyses of the precipitate (point 1) and matrix (point 2). 


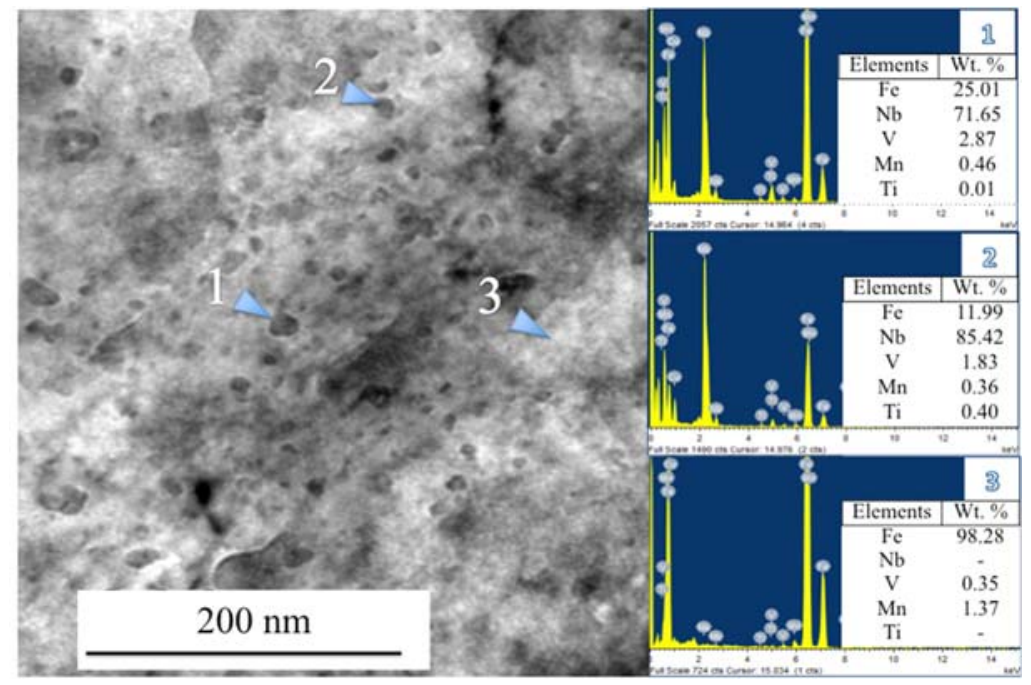

Figure 9: TEM image showing nanoprecipitates (points 1 and 2) and matrix (point 3) in the REadded steel along with their EDS results.

Table 4 shows that, compared to the base steel, the lower yield stress is higher for REadded steel. The stress level at this point which usually continues with small fluctuations at a nearly constant stress (especially in RE-added steel) is described as the stress to drive plastic deformation towards the still unyielded region of the material $[19,50]$. Therefore, compared to the base steel, it seems that the strengthening mechanisms achieved by RE addition, e.g. grain refinement and nanoprecipitaion, have probably led to an enhanced lower yield point for RE-added steel. After this point, the band propagates through the length of the sample.

Comparing the tensile curves shown in Figure $\mathbf{6 c}$ and $\mathrm{d}$, it can be apprehended that the appearance of oscillations during the Lüders strain, before the start of uniform plastic flow, is different in the two studied steels. In fact, zone B can be considered as the most different zone between the tensile behavior of the base and RE-added steels. A schematic illustration of how the uniform propagation of Lüders band takes place during the Lüders strain is indicated by points 1-3 in Figure 10, which corresponds to the enlarged stressstrain curve shown in Figure 6d. It is known that for the occurrence of the plastic deformation, tangential stresses acting at the angle of around $45^{\circ}$ to the direction of the force are required [19]. Accordingly, in Figure 10, the deformation bands are drawn with angle of $45^{\circ}$. Plastic deformation takes place locally in deformation bands, starting at nucleation points (point 1 in Figure 10) and then spreading out towards the still unyielded part of the specimen. If the tensile specimen undergoes a uniform propagation of Lüders bands, at the end of this stage, the length of the specimen would be uniformly covered by the plastic deformation bands (point 3 in Figure 10), which probably occurred in RE-added steel. In this way, the entire sample is gradually deformed to a certain amount of deformation (Lüders strain).

Compared to the base steel, this area (B) seems to be smoother and wider for RE-added steel. In the case of low carbon (ferrite-pearlite) steels, Tsuchida et al. [21] reported that the Lüders strain increases with a decrease in the ferrite grain size at a given temperature. Moreover, Varin et al. [51] suggested that the presence and distribution of fine precipitates would enlarge the Lüders area. Table $\mathbf{3}$ shows that, compared to the base steel, 
ferrite grain size is finer in RE-added steel. Besides, comparing Figure $\mathbf{8}$ with Figure 9, it seems that $\mathrm{RE}$ addition would promote the $\mathrm{Nb}$-nanoprecipitation. Both of these consequences can explain the wider Lüders deformation region obtained for RE-added steel.

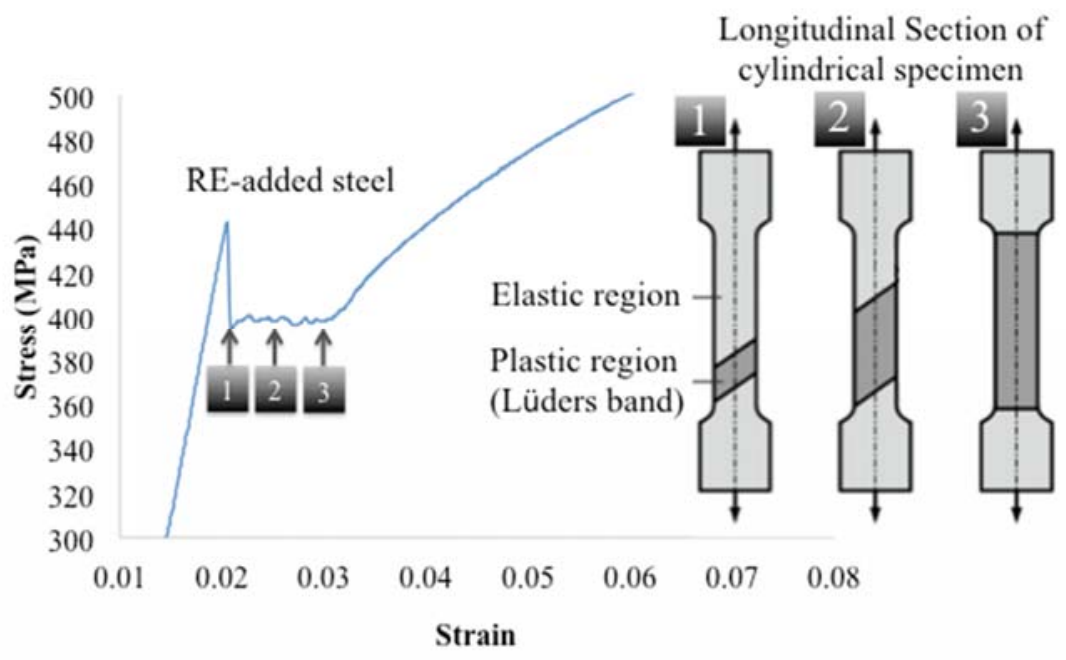

Figure 10: Division of area B in the tensile curve of RE-added steel and corresponding schematic illustration of the Lüders band through the length of the sample.

Regarding the difference in the shape of the oscillations within zone B (Figure $6 \mathrm{c}$ and d), Van Rooyen [50] claimed that the uniformity in structure and dimension of the specimens would affect the type (shape) of Lüders strain region. In addition to these criteria, it has been stated that the interstitial atoms, strain rate, and test temperature would also affect the shape of zone B. Since the dimensions of the tensile specimen and test conditions (test temperature and strain rate) have been exactly the same for the studied steels, the difference between zone B observed for the base and RE-added steels might be attributed to the uniformity in structure and composition of the samples. Based on this explanation, inhomogeneous plastic deformation (rough fluctuations) within area B observed in the tensile curve of the base steel (Figure $\mathbf{6 c}$ ) could be attributed to the non-uniform formation of Lüders bands (non-uniform stress concentration in Lüders front) derived from the nonuniform distribution of nanoprecipitates (Figure 8) as well as interstitial, e.g. C, atoms. In this regard, Liu et al. [20] have reported that in the steel with uniform distribution of $\mathrm{Nb}$ precipitates, during reheating, more carbon atoms have been released for the formation of the Cottrell's atmosphere. While in steels with precipitates formed at the grain boundaries or linked to the preexisted large precipitates, lower amount of interstitial atoms in the matrix would promote continuous yielding points [20]. In other words, when the fine $\mathrm{Nb}$ precipitates are uniformly distributed in the matrix, carbon depletion zones would be limited to a small area and reheating would cause dissolution of these precipitates which would release $\mathrm{C}$ and $\mathrm{Nb}$ free in the matrix. This, in turn, would motivate the Cottrell's atmosphere and consequently the Lüders bands, although, Nb-precipitates themselves would promote the Cottrell's atmosphere in such low carbon steels. The reheating process may include the austenitization stage in homogenizing or normalizing treatment. Same idea can be found elsewhere, in which, $\mathrm{Nb}$ addition to a low carbon steel caused appearance and motivation of yield point phenomenon [19, 47, 48]. 
Based on these explanations, one can conclude that large accumulation/segregation of $\mathrm{NbC} / \mathrm{Nb}(\mathrm{C}, \mathrm{N})$ around $\mathrm{MnS}$ in the base steel (Figure 3 and Figure 5) has probably consumed significant amount of solute $\mathrm{C}$ and $\mathrm{Nb}$ in the matrix, causing a non-uniform distribution of depletion zones around these particles in the matrix. Therefore, it seems that such a uniform propagation of Lüders bands observed in Figure $\mathbf{1 0}$ or Figure $\mathbf{6 d}$, has not taken place in the base steel (Figure $\mathbf{6 c}$ ), which turn into rough fluctuations in stress level through zone B. In contrast, it can be suggested that the uniform distribution of the solute carbon atoms and $\mathrm{Nb}$-precipitates in the matrix of RE-added steel resulted in uniform plastic deformation within area B (Lüders deformation in Figure 6d).

Table 4 shows that RE addition could increase the total elongation of the studied steel from 25 to $32 \%$. In the normalized low carbon steels, the grain size of ferrite/matrix has a major impact on the elongation of the steel. The results given in Table 3 demonstrate that the normalized microstructure (ferrite+pearlite) is finer in the presence of RE; the contribution of RE addition to the refinement of the microstructure was discussed in subsection 3.1.1. Although, as mentioned above (section 3.2), a decrease in ferrite grain size would increase the Lüders elongation/strain, it has been reported in the scientific literature by many authors that the uniform elongation decreases as the grain size is reduced $[52,53]$. Therefore, taking into account that the balance between the amounts of ferrite/pearlite phases is very similar in both steels (Table 3 ) and, based on these previous reports, it is unexpected to find that a reduction in the ferrite/pearlite nodule size in the RE-added steel increases the elongation. However, in addition to the effect of the matrix grain size on the total elongation, there are other microstructural features that would also influence this property. For instance, it has been suggested that morphology and nature of the inclusions would affect the elongation of steels; the inclusions with good bonding to the matrix and/or with lower area fraction and more spherical shape are beneficial to the steel elongation $[54,55]$. The inclusions with sharp faceted shapes would provide the stress concentration and thus crack initiation centers, leading to premature failure which, in turn, would lower the elongation. In this regard, it has been mentioned in a recent work of the authors that RE addition to a same low carbon steel led to the formation of more spherical inclusions with lower fraction and smaller size [33]. In another study, it has been found out that RE-particles have a good bonding with the matrix, while there is a gap surrounding the dominant inclusion, i.e. $\mathrm{MnS}$, present in the base steel [36]. This gap/debonded area would serve as stress concentration site, leading to the formation of cracks during the tensile test. This debonded area has been considered as one of the main reasons explaining the lower impact toughness of the base steel, compared to RE-added steel [36]. Thus, in the same way as for the impact tests, this gap/debonded area would explain this premature failure of the tensile samples corresponding to the base steel, in spite of its finer matrix grain size.

\section{Conclusions:}

The rationale of the present work is to provide insight into the effects of RE addition on the tensile behavior of a low carbon $\mathrm{Nb}$-containing microalloyed steel which confronts the yield point phenomenon during the tensile test. Regarding the fact that the elimination of this phenomenon is desired for some applications, the presented evidences bring about specific advantages and drawbacks of the RE addition which can be summarized as 
follows:

1. Yield point phenomenon has taken place during the tensile test of the both base and RE-added steels while their behavior, especially within the Lüders region, have been different.

2. The RE addition seems to enhance the upper and lower yield points of the studied steel by: i) refining the final ferrite+pearlite microstructure and ii) promoting an extensive distribution of the $\mathrm{Nb}$ nanoprecipitates in the ferritic matrix.

3. The larger Lüders strain of the RE-added steel, compared to the base steel, would be explained based on the finer microstructure of the RE-added steel and the extensive $\mathrm{Nb}$-precipitation present in the matrix.

4. Lüders bands have uniformly propagated through the length of the RE-added sample, while rough oscillations in stress level during the Lüders region of the base steel can be attributed to the non-uniform distribution of $\mathrm{Nb}$-precipitates and also $\mathrm{C}$ in solid solution as significant amount of $\mathrm{Nb}$-rich phases had been accumulated around $\mathrm{MnS}$ in the base steel.

5. The effect of RE addition on the UTS of the studied steel has been negligible which might be due to the same work hardening behavior of the base and RE-added steels; it is suggested that $200 \mathrm{ppm}$ of RE has not been able to alter the work hardening rate of the ferrite matrix.

6. The inclusions with more spherical shape and lower area fraction obtained by the RE addition would explain the higher total elongation of RE-added steel, compared to the base steel; the gap/debonded area surrounding the MnS particles, present in the base steel, might lead to a premature fracture.

\section{Acknowledgments:}

The authors from the University of Tehran gratefully acknowledge the financial support provided by the Office of International Affairs and the Office of Research Affairs, College of Engineering, for the project number 8107009.6.34. The authors from CENIMCSIC would like to acknowledge the financial support from Comunidad de Madrid through DIMMAT-CM_S2013/MIT-2775 Project. The authors are grateful to the Phase Transformations and Microscopy labs from CENIM-CSIC. Mr. Javier Vara Miñambres from the Phase Transformations lab (CENIM-CSIC) is gratefully acknowledged for his continuous experimental support. The authors also acknowledge ICTS-Centro Nacional de Microscopía Electrónica (CNME) and Mr. Esteban Urones Garrote for the experimental supports in TEM lab. 


\section{References:}

[1] J.R. Davis, Alloying: Understanding the Basics, ASM International, Materials Park, Ohio, USA, 2001.

[2] S. Vervynckt, K. Verbeken, B. Lopez, J.J. Jonas, Modern HSLA steels and role of non-recrystallisation temperature, International Materials Reviews 57(4) (2012) 187207.

[3] J. Rassizadehghani, H. Najafi, M. Emamy, G. Eslami-Saeen, Mechanical Properties of V-, Nb-, and Ti-bearing As-cast Microalloyed Steels, J. Mater. Sci. Technol. 23(06) (2007) 779-784.

[4] H. Najafi, J. Rassizadehghani, S. Norouzi, Mechanical properties of as-cast microalloyed steels produced via investment casting, Mater. Des 32(2) (2011) 656663.

[5] K.Y. Xie, T. Zheng, J.M. Cairney, H. Kaul, J.G. Williams, F.J. Barbaro, C.R. Killmore, S.P. Ringer, Strengthening from Nb-rich clusters in a Nb-microalloyed steel, Scr. Mater. 66(9) (2012) 710-713.

[6] E.J. Mittemeijer, Fundamentals of materials science: microstructure-property relationships using metals as model systems, Int. Heat Treat. Surf. Eng 5(4) (2011) 139-139.

[7] M. Charleux, W.J. Poole, M. Militzer, A. Deschamps, Precipitation behavior and its effect on strengthening of an HSLA-Nb/Ti steel, Metall. Mater. Trans. A 32(7) (2001) 1635-1647.

[8] H. Najafi, J. Rassizadehghani, S. Asgari, As-cast mechanical properties of vanadium/niobium microalloyed steels, Mater. Sci. Eng. A 486(1-2) (2008) 1-7.

[9] V.V. Sosnin, A.M. Longinov, I.V. Barantseva, N.A. Povkova, I.V. Lyasotskii, Distribution of niobium and titanium carbonitrides in continuous-cast microalloy steels, Steel Transl 40(6) (2010) 590-594.

[10] C.Y. Chen, H.W. Yen, F.H. Kao, W.C. Li, C.Y. Huang, J.R. Yang, S.H. Wang, Precipitation hardening of high-strength low-alloy steels by nanometer-sized carbides, Mater. Sci. Eng. A 499(1-2) (2009) 162-166.

[11] D. San Martin, F.G. Caballero, C. Capdevila, C. Garcia de Andres, Austenite grain coarsening under the influence of niobium carbonitrides, Mater. Trans. 45(9) (2004) 2797-2804.

[12] J. Vivas, C. Celada-Casero, D. San Martín, M. Serrano, E. Urones-Garrote, P. Adeva, M.M. Aranda, C. Capdevila, Nano-precipitation strengthened G91 by thermomechanical treatment optimization, Metall. Mater. Trans. A 47(11) (2016) 5344-5351.

[13] S.H. Mousavi Anijdan, A. Rezaeian, S. Yue, The effect of chemical composition and austenite conditioning on the transformation behavior of microalloyed steels, Mater. Charact. 63 (2012) 27-38. 
[14] O.P. Modi, N. Deshmukh, D.P. Mondal, A.K. Jha, A.H. Yegneswaran, H.K. Khaira, Effect of interlamellar spacing on the mechanical properties of $0.65 \% \mathrm{C}$ steel, Mater. Charact. 46(5) (2001) 347-352.

[15] B.L. Bramfitt, Structure/Property Relationships in Irons and Steels, in: J.R. Davis (Ed.), Materials Selection and Design, ASM Handbook, ASM International1998, pp. $153-173$.

[16] B. Garbarz, F.B. Pickering, Effect of pearlite morphology on impact toughness of eutectoid steel containing vanadium, Mater. Sci. Technol. 4(4) (1988) 328-334.

[17] K.K. Ray, D. Mondal, The effect of interlamellar spacing on strength of pearlite in annealed eutectoid and hypoeutectoid plain carbon steels, Acta Metall. Mater. 39(10) (1991) 2201-2208.

[18] Y. Liang, Z.Y. Shi, Y.L. Liang, Effects of Ce or $\mathrm{Nb}$ addition on nucleation of pearlite in high carbon steel, Adv Mat Res. 734-737 (2013) 1531-1535.

[19] S. Rešković, I. Jandrlić, Influence of niobium on the beginning of the plastic flow of material during cold deformation, The Scientific World Journal 2013 (2013) 5.

[20] Z.Y. Liu, F. Gao, L.Z. Jiang, G.D. Wang, The correlation between yielding behavior and precipitation in ultra purified ferritic stainless steels, Mater. Sci. Eng. A 527(16) (2010) 3800-3806.

[21] N. Tsuchida, Y. Tomota, K. Nagai, K. Fukaura, A simple relationship between Lüders elongation and work-hardening rate at lower yield stress, Scr. Mater. 54(1) (2006) 57-60.

[22] F. Pan, J. Zhang, H.L. Chen, Y.H. Su, C.L. Kou, Y.H. Su, S.H. Chen, K.J. Lin, P.H. Hsieh, W.S. Hwang, Effects of rare earth metals on steel microstructures, Materials 9 (2016) 417-436.

[23] Q. Ma, C. Wu, G. Cheng, F. Li, Characteristic and formation mechanism of inclusions in 2205 duplex stainless steel containing rare earth elements, Mater. Today: Proc. 2 (2015) 300-305.

[24] M. Opiela, M. Kamińska, Influence of the rare-earth elements on the morphology of non-metallic inclusions in microalloyed steels, JAMME 47(2) (2011) 149-156.

[25] L.M. Wang, Q. Lin, L.J. Yue, L. Liu, F. Guo, F.M. Wang, Study of application of rare earth elements in advanced low alloy steels, J. Alloys Compd. 451(1-2) (2008) 534-537.

[26] A.F. Belyakova, Y.V. Kryankovskii, I.V. Paisov, Effect of rare earth metals on the structure and properties of structural steel, Met. Sci. Heat Treat. 7(9) (1965) 588-593.

[27] K.J. Handerhan, W.M. Garrison, Effects of rare earth additions on the mechanical properties of the secondary hardening steel AF1410, Scr. Metall. 22(3) (1988) 409412.

[28] S. Zhang, Y. Yu, S. Wang, H. Li, Effects of cerium addition on solidification structure and mechanical properties of 434 ferritic stainless steel, J RARE EARTH 35(5) (2017) 518-524. 
[29] R. Tuttle, Effect of rare earth additions on grain refinement of plain carbon steels, IJMC 6(2) (2012) 51-65.

[30] M.W. Garrison Jr., L.J. Maloney, Lanthanum additions and the toughness of ultrahigh strength steels and the determination of appropriate lanthanum additions, Mater. Sci. Eng. A 403(1-2) (2005) 299-310.

[31] X. Chen, Y. Li, Fracture toughness improvement of austempered high silicon steel by titanium, vanadium and rare earth elements modification, Mater. Sci. Eng. A 444(12) (2007) 298-305.

[32] H. Torkamani, S. Raygan, C. Garcia-Mateo, J. Rassizadehghani, Y. Palizdar, D. SanMartin, Evolution of pearlite microstructure in low-carbon cast microalloyed steel due to the addition of La and Ce, Metall. Mater. Trans. A 49(10) (2018) 4495-4508.

[33] H. Torkamani, S. Raygan, C. Garcia Mateo, J. Rassizadehghani, J. Vivas, Y. Palizdar, D. San-Martin, The influence of La and Ce addition on inclusion modification in cast niobium microalloyed steels, Metals 7(9) (2017) 377-395.

[34] H.L. Liu, C.J. Liu, M.F. Jiang, Effect of rare earths on impact toughness of a lowcarbon steel, Mater. Des 33 (2012) 306-312.

[35] H.L. Liu, C.J. Liu, M.F. Jiang, Effects of rare earths on the austenite recrystallization behavior in X80 pipeline steel, Adv Mat Res. 129-131 (2010) 542-546.

[36] H. Torkamani, S. Raygan, C. Garcia Mateo, J. Rassizadehghani, Y. Palizdar, D. SanMartin, Contributions of rare earth element $(\mathrm{La}, \mathrm{Ce})$ addition to the impact toughness of low carbon cast niobium microalloyed steels, Met. Mater. Int. (2018).

[37] A.R. Marder, B.L. Bramfitt, Effect of continuous cooling on the morphology and kinetics of pearlite, Metall. Trans. A 6(11) (1975) 2009-2014.

[38] A.R. Marder, B.L. Bramfitt, The effect of morphology on the strength of pearlite, Metall. Trans. A 7(3) (1976) 365-372.

[39] R.E. Smallman, R.J. Bishop, Chapter 8 - Strengthening and toughening, Modern Physical Metallurgy and Materials Engineering (Sixth Edition), ButterworthHeinemann, Oxford, 1999, pp. 259-296.

[40] H. Drar, Metallographic and fractographic examination of fatigue loaded PM-steel with and without MnS additive, Mater. Charact. 45(3) (2000) 211-220.

[41] R. Schwab, V. Ruff, On the nature of the yield point phenomenon, Acta Mater. 61(5) (2013) 1798-1808.

[42] R.E. Hook, J.A. Elias, The effects of composition and annealing conditions on the stability of columbium (niobium)-treated low-carbon steels, Metall. Trans. 3(8) (1972) 2171-2181.

[43] P. Marshall, Austenitic Stainless Steels: Microstructure and mechanical properties, Springer Netherlands 1984.

[44] G.E. Totten, Steel Heat Treatment: Metallurgy and Technologies, Taylor \& Francis 2006. 
[45] W.B. Morrison, The effect of grain size on the stress-strain relationship in low carbon steel, Trans. ASM 59 (1966) 824-846.

[46] R. Silva, A. Pinto, A. Kuznetsov, I. Bott, Precipitation and grain size effects on the tensile strain-hardening exponents of an API X80 steel pipe after high-frequency hotinduction bending, Metals 8(3) (2018) 168.

[47] S. Rešković, I. Jandrlić, F. Vodopivec, Influence of testing rate on Lüders band propagation in niobium microalloyed steel, Metalurgija 55(2) (2016) 157-160.

[48] I. Jandrlić, S. Rešković, F. Vodopivec, Determining the amount of Lüders band in niobium microalloyed steel, Metalurgija 55(4) (2016) 631-634.

[49] J. Adamczyk, Development of the microalloyed constructional steels, JAMME 14(12) (2006) 9-20.

[50] G.T. Van Rooyen, Basic factors which influence the Lüders strain during discontinuous yielding, Mater. Sci. Eng. 7(1) (1971) 37-48.

[51] R.A. Varin, B. Mazurek, D. Himbeault, Discontinuous yielding in ultrafine-grained austenitic stainless steels, Mater. Sci. Eng. 94 (1987) 109-119.

[52] N. Tsuchida, H. Masuda, Y. Harada, K. Fukaura, Y. Tomota, K. Nagai, Effect of ferrite grain size on tensile deformation behavior of a ferrite-cementite low carbon steel, Mater. Sci. Eng. A 488(1) (2008) 446-452.

[53] Y. Tomota, A. Narui, N. Tsuchida, Tensile behavior of fine-grained steels, SIJ Int. 48(8) (2008) 1107-1113.

[54] P.A. Thornton, The influence of nonmetallic inclusions on the mechanical properties of steel: a review, J. Mater. Sci. 6(4) (1971) 347-356.

[55] Chang-Zhin Wu, T.-S. Shih, Effects of inclusion particles on the microstructure and mechanical properties of high strength austempered ductile iron, Mater. Trans. 44 (5) (2003) 995-1003. 